\title{
14 Saran Esensial Bagi Pengusaha
}

\section{Dea Ismani Yuliarti}

\author{
Universitas Nahdlatul Ulama Sidoarjo \\ deaismani@protonmail.com
}

\begin{abstract}
Menjadi pengusaha adalah impian bagi banyak orang tetapi hanya kenyataan bagi sebagian orang dan kenyataan jangka panjang bagi lebih sedikit orang. Sebagian besar yang berhasil memiliki pemahaman yang mendalam tentang bidang bisnis dan juga sejumlah ikatan bisnis. Tetapi bagaimana Kamu meningkatkan peluang Kamu untuk menjadi sukses?. Kami ingin memberitahu Kamu bahwa kami memiliki resep ajaib. Lalu kami bisa botolkan dan mendistribusikannya ke semua orang. Pekerjaan kami sebagai panduan akan jauh lebih sederhana!. Keberhasilan wirausaha adalah kombinasi dari beberapa faktor. Tulisan ini akan memberikan beberapa tips dan saran esensial bidang wirausaha bagi kamu.
\end{abstract}




\section{Konsisten}

Pengusaha muda harus memahami pentingnya konsisten. Menjalankan bisnis tidak dapat diprediksi, menantang dan tidak seperti pekerjaan dari jam 9-ke-5 sore. Kamu harus membuat jadwal dan menaatinya. Jangan hanya menjadi sukses dalam semalam, Kamu harus membuat rencana untuk sukses. Ikuti jadwal Kamu, buat tujuan dan secara konsisten melakukan tugas-tugas yang diperlukan untuk melaksanakan rencana Kamu. Ingatlah bahwa menjadi konsisten tidak hanya terbatas pada kehidupan profesional Kamu. Kamu harus konsisten dalam kehidupan pribadi Kamu juga. Jika Kamu memiliki tugas dan pekerjaan rumah untuk sekolah, Kamu perlu memastikan bahwa Kamu menyelesaikan semua itu, sehingga Kamu dapat mengerjakan ide bisnis Kamu. Lakukan apa yang harus Kamu lakukan, sehingga Kamu dapat melakukan apa yang ingin Kamu lakukan (Emerson, 2017).

\section{Jadilah Sehat}

Kamu mungkin pernah memiliki wirausaha sebagai gaya hidup, bukan pekerjaan / profesi jam 9 hingga 5 sore. Ya! Kamu sudah benar, itu memang gaya hidup. Kesehatan Kamu adalah aset paling penting 
sebagai wirausahawan. Tentu saja, ketika memulai bisnis pertama Kamu ada banyak hal yang dapat membuat Kamu stres dan kelelahan. Kamu perlu sesuatu untuk menghilangkan stres dan makan dengan benar, berolahraga secara teratur dan memiliki waktu untuk Kamu akan melakukan keajaiban dalam hidup Kamu (Kleim, 2018).

\section{Bersikap Keras Kepala}

Sering terjadi bahwa wirausahawan menerima tugas yang di luar misi perusahaan mereka. Mengapa? Hanya karena mereka harus membayar tagihan mereka, seperti orang lain! Masuk akal, bukan?. Semua orang harus makan. Meskipun kadang-kadang mungkin perlu untuk menjauh dari misi dan tujuan perusahaan Kamu, ada risiko hal ini dapat secara perlahan mengubah perusahaan Kamu. Biarkan kita jelaskan. Seiring waktu, dengan menerima tugas yang tidak sesuai dengan apa yang benar-benar ingin Kamu lakukan, sangat besar kemungkinan Kamu akan secara bertahap menjadi ahli di bidang itu terlepas dari diri Kamu sendiri. Kamu akan mendapatkan proyek yang membawa Kamu keluar dari bidang minat dan kekuatan Kamu. Kamu akan lelah, dan tanpa menyadarinya, Kamu akan 
mengembangkan perusahaan yang tidak menyerupai proyek bisnis yang Kamu harapkan. Kami tidak selalu memiliki kemewahan menolak kontrak, kita setuju. Namun, Kamu harus belajar mengembangkan ketegasan tertentu terkait visi bisnis Kamu. Semakin Kamu berangkat dari itu, semakin Kamu akan menyebarkan energi dan sumber daya perusahaan, dan semakin sedikit Kamu akan merasa termotivasi sehubungan dengan proyek Kamu. Bayangkan jika Kamu menerima kontrak semacam ini dan kemudian, minggu berikutnya, wajib menolak proyek yang menggairahkan Kamu karena Kamu kelebihan beban. Bukankah itu sangat menyedihkan? Logika yang sama berlaku untuk kolaborasi, aliansi pemasaran atau proyek yang paralel dengan perusahaan Kamu. Ada tiga aturan untuk memulai bisnis: konsistensi, konsistensi, dan konsistensi. Bersikap keras kepala, pergi untuk proyek yang menarik minat Kamu, dan tetap fokus pada tujuan akhir Kamu. Merek apa yang ingin Kamu ciptakan? Di bidang apa Kamu ingin dikenal?. Siapa yang ingin kamu layani? Dengan cara apa?. Apa kepribadian perusahaan Kamu? (L'Écuyer, 2016). 


\section{Pelajari Kekuatan Berkata Tidak}

Hanya mengalokasikan waktu Kamu untuk tugas-tugas yang paling berharga, yang membantu Kamu memenuhi tujuan Kamu. Terkadang, ini bisa berarti mengatakan "Tidak" pada proyek, klien, atau tanggung jawab baru yang tidak akan membesarkan Kamu ke arah yang Kamu inginkan (DiScala, 2017).

\section{Teliti Kesenjangan Konsumen}

Siapa yang menaklukkan ini sebelumnya?. Apa yang bisa kami pelajari dari mereka? (Meis, 2017).

\section{Tinggalkan Egomu di Depan Pintu}

Kewirausahaan adalah perjalanan yang sangat sederhana. Itu diisi dengan kemenangan kecil dan pukulan kecil, dan satu truk penuh ketidakpastian. Keyakinan dan harga diri adalah kunci untuk mengatasi badai dan menunjukkan ketahanan. Tetapi jika Kamu membiarkan ego Kamu menghalangi, Kamu tidak akan siap untuk mengambil langkahlangkah yang diperlukan untuk berhasil. Itu mungkin perlu melakukan pekerjaan sepele, mengirim email dingin, meminta nasihat kepada pengusaha yang lebih berpengalaman atau mendengarkan pelanggan Kamu untuk 
menantang asumsi Kamu. Pada Hari 1, Kamu tidak akan berurusan dari posisi yang kuat jadi belajarlah untuk menerimanya. Merangkul kerentanan Kamu akan membuat Kamu lebih kuat. Kamu tidak bisa menjadi ahli dalam segala hal dan bagian dari keinginan untuk menjadi wirausaha adalah keinginan untuk mempelajari hal baru setiap hari. Jangan takut bertemu orang yang lebih berpengalaman atau lebih pintar dari Kamu. Jangan takut untuk menguji suatu produk ketika itu setengah matang dan Kamu sedikit malu akan hal itu. Kamu akan belajar dari kesalahan Kamu dan Kamu akan tumbuh secara eksponensial, baik secara profesional maupun pribadi. Itulah yang membuat perjalanan ini sangat berharga (Mérineau, 2017).

\section{Ketika Kamu Mencapai Kesuksesan dalam Bisnis, Ingatlah untuk Membayarnya dengan Membantu Orang Lain}

Pendidikan wirausaha bertujuan menyampaikan ilmu dan mentransformasi orang lain menjadi pengusaha yang lebih baik (Fidiana, et al., 2017). Setiap manusia yang memiliki ilmu termasuk ilmu wirausaha selayaknya harus mengamalkan ilmu tersebut (Asitah et al., 2017). Hanya ada dua cara bagi 
seseorang untuk belajar tentang sesuatu yang mereka bahkan tidak pernah tahu mereka tidak tahu. Yang pertama, mereka mencari jalan keluar yang sulit. Kami di dunia wirausaha menyebut sekolah itu ketukan keras. Satusatunya cara untuk menyelesaikannya adalah meminta seseorang membimbing mereka, melatih mereka, atau membagikan pengetahuan mereka kepada mereka. Jadi, alih-alih orang harus menemukan kembali roda, atau mencari tahu hal-hal kesalahan terpanjang, paling sulit, paling mahal melalui kesalahan, kita yang memiliki memiliki pengetahuan - bukan hanya kita yang seharusnya, kami merasa bahwa kita memiliki tanggung jawab untuk membagikan itu (Basu, 2018).

\section{Ibadah kepada Tuhan}

Tips mengelola institusi pendidikan wirausaha adalah niat mendidik dan berjuang karena Allah ta'ala. Niscaya rintangan sebesar apapun akan terasa ringan dihadapan kita (Yuniarti et al., 2017). Pemimpin wirausaha harus seperti Ilmu Nahwu dalam Bahasa Arab yaitu harus bisa Marfu' (dhummah) dan Manshub (fathah), jangan seperti Majrur dan Majzum. Marfu' yang berarti memeluk atau 
merangkul, sedangkan Manshub yang berarti terbuka tanpa ada yang ditutupi (Maula et al., 2017; Qori'ah et al., 2017). Wirausaha senantiasa harus selalu berpegang teguh pada sifat yang dimiliki oleh Rasul yaitu jujur, amanah, fathana, siddiq selain itu juga harus bermodal ikhlas, karena Allah ingin agamanya itu di amalkan, poin yang kedua yaitu do'a para alim dan ulama terdahulu lah yang sangat penting dan point yang ke tiga yaitu transparan kepada semua orang agar sesuatu yang di kerjakan mendapat kepercayaan dari orang lain (Munjidah, et al., 2017).

\section{Dunia Tidak Berhutang Apapun pada Kamu}

Mari kita mulai dengan kebenaran keras yang dingin: tidak ada yang peduli dengan Kamu. Ketika Kamu bekerja untuk perusahaan besar, merek dan reputasi perusahaan melakukan hal yang berat untuk Kamu. Kamu mendapatkan tiket gratis ke berbagai acara, repetisi anggur, dan makan malam dengan Kamu, dunia tampaknya berputar di sekitar Kamu Ketika Kamu meluncurkan startup Kamu, pestanya telah berakhir. Kamu sendirian. Tibatiba, tidak ada yang benar-benar peduli tentang Kamu (kecuali sesama pengusaha yang telah 
berjalan di depan sepatu Kamu sebelum Kamu). Sejak saat itu, Kamu harus mendapatkan perhatian orang. Bagaimana? Dengan bekerja keras dan menjaring jaringan pesaing Kamu. Dengan peduli sedikit lebih dari yang lain. Gairah menular. Ini adalah aset Kamu yang paling berharga terutama di awal. Energi Kamu akan membuat orang percaya pada Kamu dan proyek Kamu ketika masih tidak banyak yang bisa dipercaya (Mérineau, 2017). Bijaksana dan pantang menyerah dalam belajar dan berwirausaha adalah kunci kesuksesan hidup dan wirausaha (Nahdiyah et al., 2017).

\section{Hanya Karena Itu Bekerja untuk Orang Lain, Bukan Berarti Itu Akan Berhasil untuk Kamu}

Ajukan lebih banyak pertanyaan, selalu. Nilailah apakah "satu-satunya metode" yang dikatakan orang kepada Kamu adalah satusatunya cara untuk melakukannya, bahkan masuk akal bagi Kamu dan topik atau audiens Kamu. Kami telah menemukan lebih banyak anggota audiensi yang terlibat dan lebih banyak penjualan menunggu di sisi lain mengabaikan saran tradisional dan berfokus pada pertanyaan kunci tentang apa yang dibutuhkan 
audiens kami daripada melalui menciptakan kembali sistem yang telah digunakan orang lain. Ajukan lebih banyak pertanyaan, selalu. Apakah ini berlaku untuk Kamu? Bagaimana Kamu bisa menggunakannya tanpa elemen yang tidak Kamu sukai? Apa yang akan sangat mengejutkan audiens Kamu saat ini? Jika Kamu bertanya pada diri sendiri "Haruskah kami melakukan webinar atau tantangan 10 hari untuk mempromosikan kursus kami?", Tanyakan sebaliknya, "Di dunia di mana webinar / tantangan tidak ada, bagaimana kami idealnya membantu orang dan membagikan produk kami dengan mereka? (Basu, 2018).

\section{Bangun Reputasi Kamu}

Sukarela keterampilan dan waktu Kamu atau memelihara blog di situs web Kamu, menunjukkan daripada komunitas, yang membantu membangun kepercayaan dan membangun reputasi Kamu sebagai seorang ahli (Reynolds, 2016). Dunia dan masyarakat membutuhkan kewirausahaan (Setyawati, Purnomo, Irawan, Tamyiz, \& Sutiksno, 2018). 


\section{Branding Sangat Penting}

Lihat startup Kamu sebagai merek dari Hari 1. Tidak punya uang bukan alasan untuk membuat branding setelahnya. Mendesain secara sadar setiap interaksi yang dilakukan startup Kamu dengan pemangku kepentingan eksternal dapat berlangsung lama. Perhatian khusus pada nama Kamu, URL, desain situs web, pembuatan konten, nada dan cara kerja, posting pekerjaan, tkamu tangan email, dan semua detail penting lainnya akan membuat perbedaan besar saat mengajukan kepada calon klien atau merekrut anggota tim baru (Mérineau, 2017).

\section{Jangan Pernah Mengatakan Tidak Pernah ke Jaringan}

Jaringan adalah alat yang berharga karena dapat membantu Kamu mendapatkan investor baru, karyawan yang hebat, pelanggan baru, atau bahkan seorang mentor yang hebat. Karena itu, penting untuk menghadiri acaraacara industri dan memulai, untuk mencari bakat dan peluang baru. Linkedln telah terbukti menjadi alat yang ampuh dalam membantu kencan ke jaringan, jadi pastikan Kamu dan perusahaan Kamu memiliki kehadiran LinkedIn 
dan Kamu terus memperbarui yang sama (Chakraborty, 2017).

\section{Motivasi Dapatkan Emas}

Motivasi diri dengan wirausaha melalui belajar edupreneur (Purnomo, 2017). Sukses adalah apa yang mendefinisikan seorang pengusaha. Kamu tidak akan pernah bisa menyebut diri Kamu seorang pengusaha jika bisnis Kamu ternyata gagal. Dikatakan dan dipercaya bahwa kesuksesan menghasilkan lebih banyak kesuksesan. Singkatnya, semakin banyak Kamu mencoba dan mencapai melalui kewirausahaan, semakin banyak Kamu mulai belajar. Saat lingkungan kita mengalami transformasi cepat maka Kamu juga harus beradaptasi dengan perubahan untuk mendapatkan emas (Wrights, 2016).

\section{References}

Asitah, N., Usmawati, D.Z., Rosyidah, E., \& Purnomo, A. (2017). MI Hasyim Asy'ari IImu Harus Terus Mengarus. In Wirausaha Pendidikan Indonesia (Jilid 2). Sidoarjo: Unusida Press. 
Basu, T. (2018). Top 20 Tips for Building a Business from Successful Entrepreneurs. Retrieved May 15, 2019, from https://www.thinkific.com/blog/tips-building-abusiness-successful-entrepreneurs/

Chakraborty, R. (2017). \#7 Best Tips for First-time Entrepreneurs. Retrieved May 30, 2019, from https://www.entrepreneur.com/article/298901

DiScala, J. (2017). 8 Essential Productivity Tips for the Busy Entrepreneur. Retrieved May 19, 2019, from https://www.inc.com/johndiscala/8-essential-productivity-tips-for-busyentrepreneur.html

Emerson, M. (2017). 8 Habits to Become a Successful Young Entrepreneur. Retrieved May 25, 2019, from https://succeedasyourownboss.com/8-habitsbecome-successful-young-entrepreneur/

Fidiana, W., Istiana, Z., Rosyidah, E., Purnomo, A. (2017). MINU Waru 2 Insan Berkilau Cahaya Manfaat. In Wirausaha Pendidikan Indonesia (Jilid 4). Sidoarjo: Unusida Press.

Kleim, M. (2018). Top 10 Tips For First-Time Entrepreneurs Willing To Be Successful. Retrieved May 24, 2019, from https://smallbizsense.com/10-tips-for-first-timeentrepreneurs/ 
L'Écuyer, J.-P. (2016). Ten Tips to Becoming a Better Entrepreneur. Retrieved May 23, 2019, from https://www.futurpreneur.ca/en/2016/tentips-to-becoming-a-better-entrepreneur/

Maula, I., Mufidah, F.I., Rosyidah, E., \& Purnomo, A. (2017). SD Antawirya Islamic Javanese School Mother is Culture. In Wirausaha Pendidikan Indonesia (Jilid 1). Sidoarjo: Unusida Press.

Meis, C. (2017). 7 Tips for the Struggling Entrepreneur. Retrieved June 8, 2019, from https://www.success.com/7-tips-for-thestruggling-entrepreneur/

Mérineau, É. (2017). 17 tips for first-time entrepreneurs in 2017. Retrieved May 18, 2019, from https://medium.com/@etiennemerineau/17tips-for-first-time-entrepreneurs-in-2017e98cda59aa41

Munjidah, A, Zannah, I.P.N., Purnomo, A., Rosyidah, E. (2017). MI Thoriqussalam Berpegang Kepada Rosul. In Wirausaha Pendidikan Indonesia (Jilid 4). Sidoarjo: Unusida Press.

Nahdiyah, K., Amrina, S., Purnomo, A., \& Rosyidah, E. (2017). SD Taman Pendidikan Islam Porong Iman Kuat Bekal di Akhirat. In Wirausaha Pendidikan Indonesia (Jilid 2). Sidoarjo: Unusida Press. 
Purnomo, A. (2017). Pengertian Edupreneur. https://doi.org/10.31227/osf.io/8fnu6

Qori'ah, S., Sholikhah, S.A., Purnomo, A., \& Rosyidah, E. (2017). MI Progresif Bumi Sholawat dengan Kebenaran Semua Pasti Ada Jalan. In Wirausaha Pendidikan Indonesia (Jilid 3). Sidoarjo: Unusida Press.

Reynolds, C. (2016). 8 Tips For Becoming a Successful Entrepreneur. Retrieved June 4, 2019, from

https://www.business2community.com/strateg y/8-tips-becoming-successful-entrepreneur01567069

Setyawati, I., Purnomo, A., Irawan, D. E., Tamyiz, M., \& Sutiksno, D. U. (2018). A Visual Trend of Literature on Ecopreneurship Research Overviewed within The Last two Decades. Journal of Entrepreneurship Education, 21(4), 1-7. Retrieved from https://www.abacademies.org/articles/avisual-trend-of-literature-on-ecopreneurshipresearch-overviewed-within-the-last-twodecades-7468.html

Sholichah, S.A., Istiqomah, A., Rosyidah, E., \& Purnomo, A. (2017). MI Darun Najah Berfikir Berkarya Berdzikir. In Wirausaha Pendidikan Indonesia (Jilid 3). Sidoarjo: Unusida Press. 
Wrights, J. (2016). 5 Tips on Becoming a Successful Entrepreneur-Tactics That Can Help Your Business Grow. Retrieved May 14, 2019, from

https://www.entrepreneur.com/article/281490

Yuniarti, D., Kautsari, M.F., Sholichah, F., Purnomo, A., \& Rosyidah, E. (2017). SMP SMA Al-Amin Ponpes Bahrul Hidayah Serahkan pada Allah Ta'ala. In Wirausaha Pendidikan Indonesia (Jilid 1). Sidoarjo: Unusida Press. 